\title{
U⿱宀⿻三丨口
}

\section{Rapid determination of salicylic acid at screen printed electrodes}

Rawlinson, S., Mc Lister, A., Kanyong, P., \& Davis, J. (2018). Rapid determination of salicylic acid at screen printed electrodes. Microchemical Journal, 137, 71-77. https://doi.org/10.1016/j.microc.2017.09.019

Link to publication record in Ulster University Research Portal

\section{Published in:}

Microchemical Journal

Publication Status:

Published (in print/issue): 01/03/2018

DOI:

10.1016/j.microc.2017.09.019

\section{Document Version}

Author Accepted version

\section{General rights}

Copyright for the publications made accessible via Ulster University's Research Portal is retained by the author(s) and / or other copyright owners and it is a condition of accessing these publications that users recognise and abide by the legal requirements associated with these rights.

\section{Take down policy}

The Research Portal is Ulster University's institutional repository that provides access to Ulster's research outputs. Every effort has been made to ensure that content in the Research Portal does not infringe any person's rights, or applicable UK laws. If you discover content in the Research Portal that you believe breaches copyright or violates any law, please contact pure-support@ulster.ac.uk. 


\title{
Rapid Determination of Salicylic Acid at Screen Printed Electrodes
}

\author{
Sean Rawlinson, Anna McLister, Prosper Kanyong and James Davis ${ }^{1}$ \\ School of Engineering, Ulster University, Jordanstown, Northern Ireland, BT37 OQB
}

\begin{abstract}
The pain relief capabilities of salicylate are well established and a multitude of over the counter products populate pharmacy shelves. Over application of the preparations, through accidental or deliberate misuse, can all too often result in salicylate poisoning and, in severe cases, can be fatal. A novel detection strategy involving the quantification of the quinone byproducts arising from the electrochemical oxidation of salicylate is described. The approach has been adapted for use with a disposable screen-printed electrode and found to exhibit a high sensitivity towards salicylate which is free from the electroactive interferences that compromise the direct oxidative route. A linear range of 16 to $300 \mu \mathrm{M}$ was observed with a limit of detection of 5.6 $\mu \mathrm{M}$. The analytical applicability of the approach was demonstrated through recovery experiments of $100 \mu \mathrm{M}$ salicylate in urine.
\end{abstract}

\section{Keywords}

Salicylic Acid; Aspirin; Screen Printed Electrode; Sensor; Urine

\footnotetext{
${ }^{1}$ To whom correspondence should be addressed. T: +44(0)28 903 66407; E: james.davis@ulster.ac.uk 


\subsection{Introduction}

It has been estimated that, at any one time, some $10 \%$ of Americans suffer from acute or chronic pain - usually as a consequence of musculoskeletal injuries or disease [1-5]. Chronic pain can have a pernicious toll on everyday life placing considerable stress on the patient's family, compromises workplace capability and responsibilities and is known to be one of the principal causes of physical disability[3]. Non steroidal anti-inflammatory drugs (NSAIDS), opioids or surgery are the conventional treatment options but, in many cases, these often fail to provide long-term benefit [5-7]. It is little surprise that many will seek alternative treatments and, as a result, there is a burgeoning market (>\$100 million p.a.) in the supply of non-prescription over the counter (OTC) products that purport to provide a wealth of therapeutic benefits [8]. These take various forms such as pills, gels, ointments, lotions, sprays and, more recently, dressings and transdermal patches $[9,10]$. Salicylates are the active agent in a great many of these products but, as they can be readily acquired through sources that offer no qualified advice beyond the packaging instruction, issues over their efficacious application commonly arise [11]. While patient education and child protective caps have reduced instances of accidental misuse, data from the Toxic Exposures Survey from the American Association of Poison Control Centers (AAPCC) suggest that problems persist with $24 \%$ of analgesic-related deaths attributed to aspirin alone or in combination with other drugs. Early identification of salicylate poisoning can be life saving but, all too often, diagnosis is based on a host of secondary measurements $[12,13]$. The aim of the present communication has been to investigate the development of a modified screen printed sensor as a means of rapidly determining supratherapeutic doses of salicylate in urine.

Under normal therapeutic regimes, the metabolism of salicylate will typically involve conjugation with glycine to form salicyluric acid and with glucuronic acid to form salicyl acyl and phenolic glucuronide as indicated in Scheme 1. Oxidation of the salicylate to gentisic acid $(2,5-$ dihydroxybenzoic acid), 2,3-dihydroxybenzoic and 2,3,5-trihydroxybenzoic acids can also occur but are minor in comparison to the other routes [14-16]. These metabolites are readily excreted in the urine with the unmodified salicylate accounting for $10-30 \%$. The latter can rise significantly at large therapeutic loadings as both the glycine and glucuronide pathways have limited capacity and saturate easily [16]. The tissues become overwhelmed as a consequence and chronic salicylate toxicity can occur. It has been estimated that the plasma half-life for 
salicylate is $2-3 \mathrm{~h}$ in low doses, increasing to $12 \mathrm{~h}$ at the more usual anti-inflammatory doses. In cases where supratherapeutic doses have been administered and salicylate intoxication occurs, the half-life may be as long as 15 to $20 \mathrm{~h}$ [14-16].

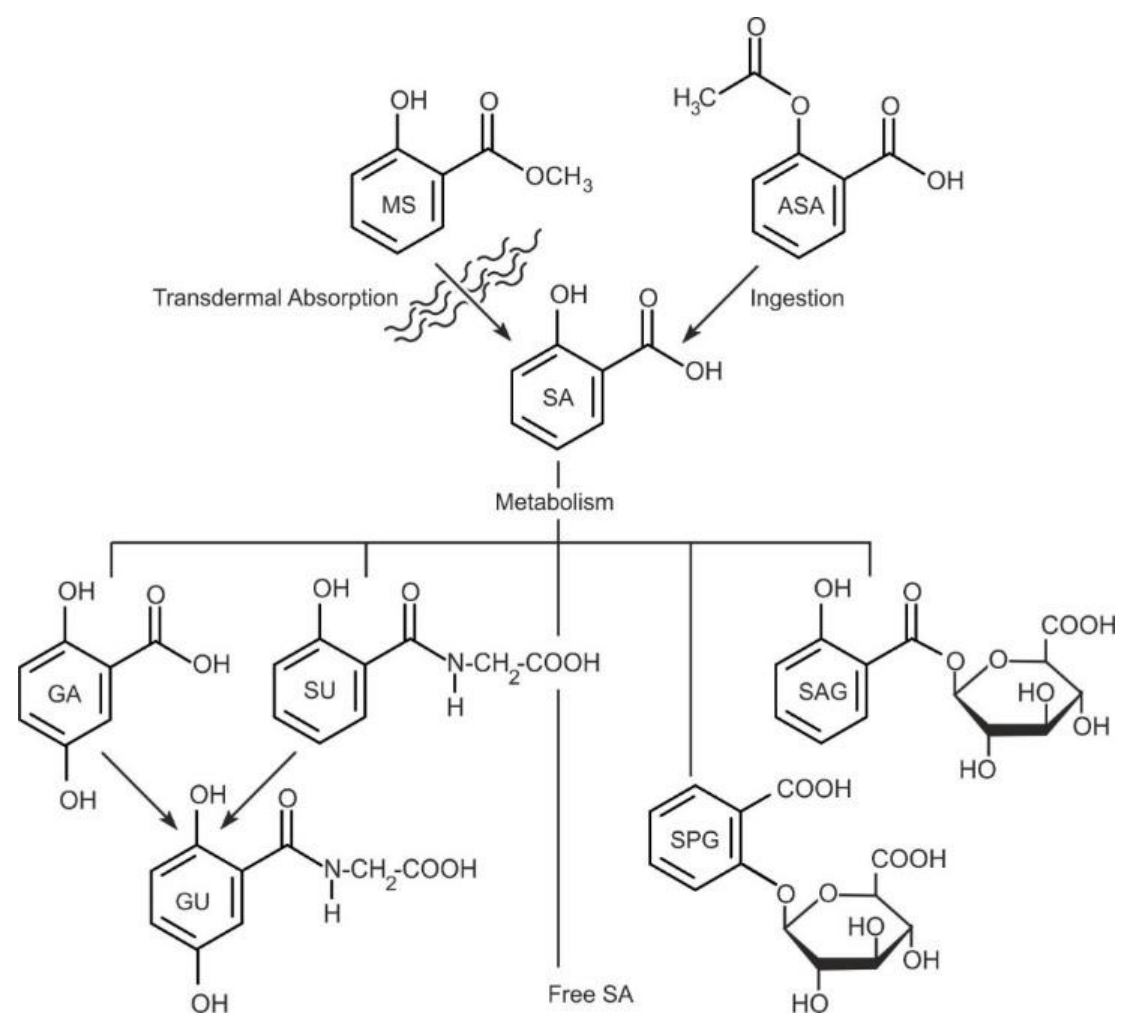

Scheme 1. Typical reaction pathways for the metabolism of salicylic acid (SA) after administration of methyl salicylate(MS) or aspirin (ASA) from OTC preparations. SPG: Salicylic Acid Phenolic Glucuronide; SAG, Salicylic Acid Acyl Glucuronide; SU, Salicyluric Acid Phenolic Glucuronide.(Adapted from [13]).

It is clear from the excretion pathways highlighted in Scheme 1 that there are several potential targets through which to assess salicylate concentration. Detection of the free, unconjugated salicylate was chosen as the principal target given its predominance at high doses consistent with poisoning.

\subsection{Methodology}

The application of electrochemical techniques to the detection of salicylic acid has traditionally been beset by a number of issues - mainly the large anodic potentials required to oxidise the 
analyte and the subsequent fouling of the electrode by oligomeric/polymeric oxidation products. A variety of approaches have been taken to minimise the effects of the latter and include: carbon electrodes [17], carbon with gold/iron oxide nanoparticles[18], gold electrodes coated with copper nanoparticles [19], platinum electrodes $[20,21]$, screen printed electrodes [22], graphene based systems[23,24] and enzyme electrodes [25,26]. Park and Eun (2016) have postulated that while passivating polymeric films can arise, a number of additional products will also be formed [27] and the various possibilities are outlined in Scheme 2.

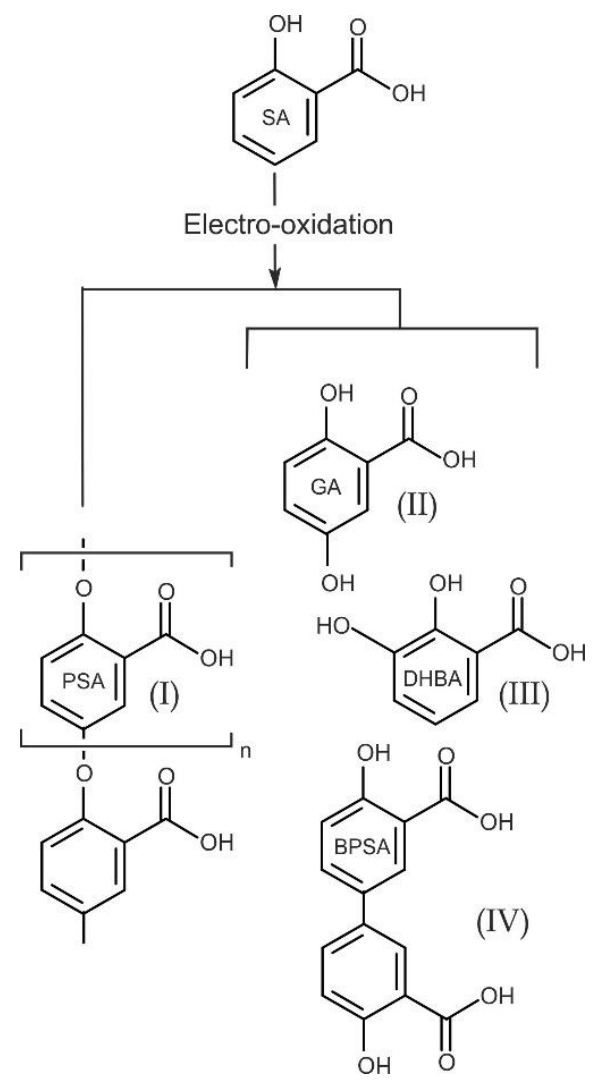

Scheme 2. Potential product spread arising from the electro-oxidation of salicylate. PSA: polymeric deposits; GA: gentisic acid; DHBA: dihydroxybenzoic acid; BPSA: biphenylsalicylic acid (Adapted from [25])

The direct oxidation of salicylate under neutral or acidic $\mathrm{pH}$ conditions will require the imposition of large anodic potentials which, as result, could induce the oxidation of other sample components and thereby compromise the accuracy of any voltammetric measurements [27]. It could be envisaged that the byproducts (II-IV) could be oxidised (or reduced) at much lower potentials thereby offering the possibility of avoiding interference from other 
electroactive species. The approach taken here was to examine the potential of using the electro-oxidation byproducts, principally the dimer BPSA, as a diagnostic marker through which to assess salicylate levels in urine.

\subsection{Experimental Details}

All chemicals were obtained from Sigma-Aldrich, were the highest grade available and were used without further purification. Electrochemical analysis was carried out using a VSP-300 Multichannel Potentiostat / Galvanostat / EIS (Bio-Logic Science Instruments, EC-Lab Ltd) with a standard three-electrode configuration with a carbon screen printed working electrode, a platinum wire counter electrode and a standard silver/silver chloride (3M NaCl, BAS Technicol UK) reference electrode. All measurements were conducted at $22^{\circ} \mathrm{C} \pm 2^{\circ} \mathrm{C}$.

Electrode Manufacture: Screen printed electrodes (SPE) were fabricated using a DEK 240 Manual Screen Printing Machine, a stainless-steel screen mesh and graphite ink (Gwent Electronic Materials (GEM) Product code: C205010697). Initially, the base of the SPE was printed onto a Valox substrate which was cured at $70{ }^{\circ} \mathrm{C}$ for $90 \mathrm{~min}$. To define the working area, a polymeric dielectric material (GEM Product code: D2071120P1) was then screen-printed onto the cured SPE. A JEOL JSM-6010 Plus scanning electron microscope (SEM) was used to characterise the surface morphology of the carbon sensors and representative micrograph of the carbon print morphology and the nanoporous nature of the deposit is highlighted in Figure 1A. The electrode array and a digital image of the working electrode disc are shown in the inset figures. The surface profile was also characterised using a DEKTAK XT Stylus Profiler (Bruker) system and the results from three electrodes are compared in Figure 1B. The typical thickness of the print is of the order of 20 micron. In principle, the array could be harnessed for the electroanalytical detection of a panel of biomarkers through sequentially addressing each electrode in turn. In this instance however, the electrodes were used on an individual basis for the detection of salicylate. 

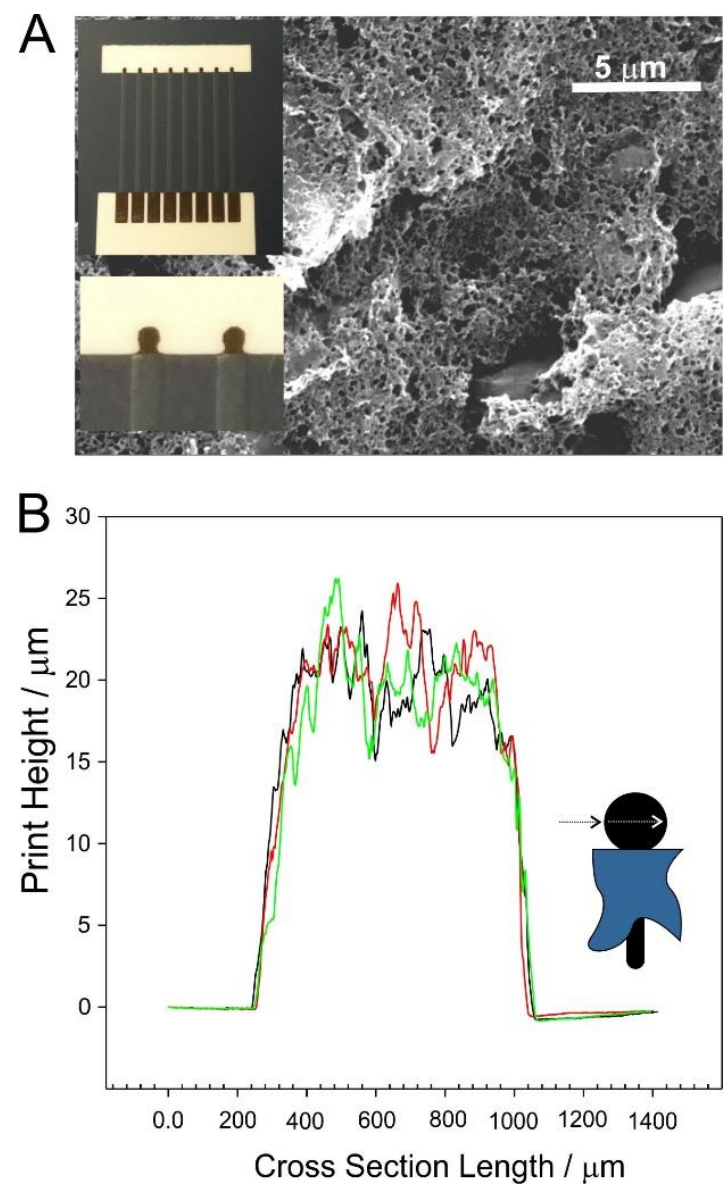

Figure 1. A) Scanning electron micrograph of the carbon surface on the working electrode disc. Inset:

Digital images of the complete printed array and the working electrodes. B) DEKTAK surface profile comparison of three working electrodes

Electrode Anodisation: It has become relatively common to electrochemically anodise carbon composite electrodes in order to elicit improved electrochemical behaviour[28,29]. The electrooxidation (+2 V, $0.1 \mathrm{M} \mathrm{NaOH}$ ) typically increases exfoliation of the carbon particles - generating more edge plane sites and increases the populations of various oxygen functional groups $[28,29]$. This process was also instituted here where it has been found that the unmodified screen printed electrodes typically exhibit poor electrochemical behaviour with large overpotentials necessary to obtain any significant analytical responses [28].

Analytical Characterisation/Ethics Approval and Compliance: The analytical capability of the SPE sensors was assessed using human urine as the test matrix. Urine was obtained from four healthy volunteers $(2 \mathrm{M}, 2 \mathrm{~F})$ who had not taken any form of medication in the 24 hours 
preceding collection of the samples and thus would be free of salicylate. The samples were collected, anonymised, stored at $4^{\circ} \mathrm{C}$ until required and then flushed to waste once the study had concluded. Approval for the use of human urine samples was granted through the Ulster University Ethics Committee (UREC Ref: REC/16/0073) prior to commencing the investigation.

\subsection{Results}

A square wave voltammogram detailing the response of an anodised screen printed electrode towards salicylate $(290 \mu \mathrm{M})$ in $\mathrm{pH} 7$ buffer is shown in Figure 2 . The peak observed at $+0.86 \mathrm{~V}$ is attributed to the oxidation of the phenol functionality with the large potential and the relatively broad nature of the peak highlighting poor electron transfer at the carbon electrode. These attributes alone would be considered a significant impediment to the development of an electrochemical sensor based on the direct oxidation of salicylate and the issues are further highlighted when considering the application of the methodology in human urine. The responses of the anodised SPE towards urine before and after the addition of salicylic acid (290 $\mu \mathrm{M})$ are presented in Figure 2 for direct comparison. A large, well defined peak dominates the profile at $+0.36 \mathrm{~V}$ and is attributed to the oxidation of urate - a common component within urine. It is important to note that beyond this initial urate peak, there is an increased background current with two further unassigned peaks at $+0.51 \mathrm{~V}$ and $+0.73 \mathrm{~V}$ resulting from the oxidation of compounds endogenous to the urine. The introduction of the salicylate (dotted line) leads to a subtle change in the voltammetric profile and a new peak at $+0.76 \mathrm{~V}$ arises. Analysis of the latter is complicated by the fact that its composition is due to the oxidation of multiple species and not simply salicylate itself. The variability in the background current arising from the presence of endogenous compounds poses a considerable challenge to the unambiguous quantification of salicylate through direct oxidation and it is clear that an alternative approach is required.

The electrooxidation of the salicylate is known to lead to the production of hydroquinone species (GA, DHBA and BPSA etc) as indicated previously in Scheme 2 . It could be anticipated that the latter should be capable of oxidation at lower potentials than the parent salicylate and therefore it was envisaged that through targeting these byproducts, an indirect measure of the initial salicylate concentration could be obtained which would be less susceptible to interference. It has been suggested by Park and Eun that the hydroquinone dimer 
(BPSA, structure IV in Scheme 2) is the predominate product of salicylate oxidation in alkaline solution [27] and therefore the efficacy of selecting this target/electrolyte combination as a viable detection methodology was investigated.

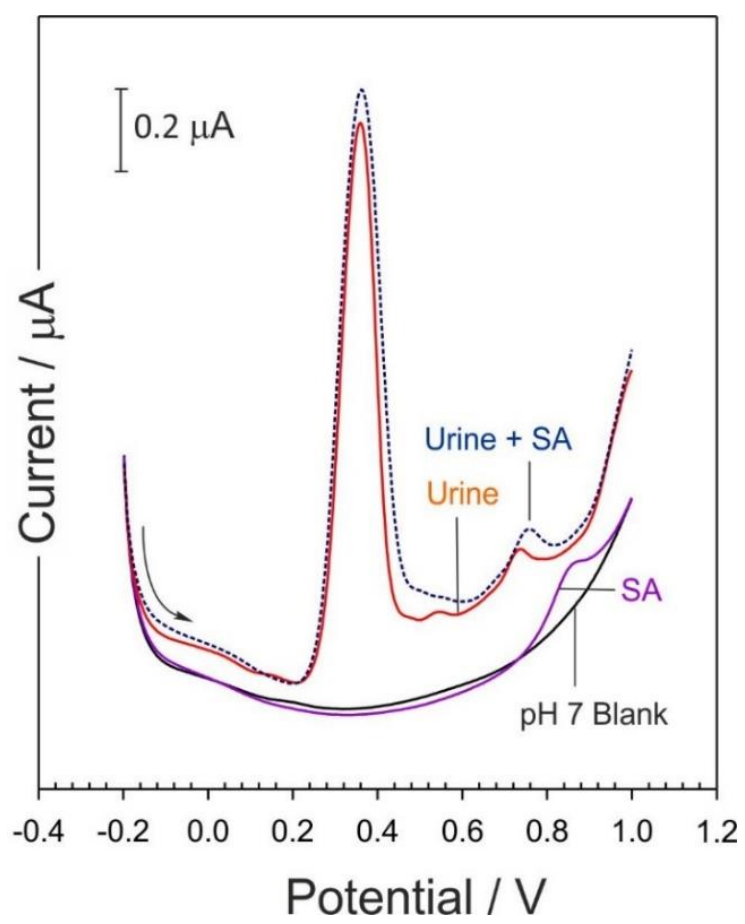

Figure 2. Square wave voltammograms detailing the response of an anodised screen printed electrode towards human urine in the absence and presence of salicylic acid (290 $\mu \mathrm{M})$.

\subsection{Electrogenerated Dimer Detection}

Cyclic voltammetry was initially used to investigate the electrode processes arising from the oxidation of salicylic acid and to provide some diagnostic data on the subsequent electrogenerated byproducts. Voltammograms detailing the response of an anodised screen printed electrode towards the oxidation of salicylic acid $(10 \mathrm{mM})$ in $0.1 \mathrm{M} \mathrm{NaOH}$ are detailed in Figure 3. The response recorded at an unmodified electrode are shown in the inset figure for comparison. The use of $\mathrm{NaOH}$ as the electrolyte was chosen as Park and Eun (2017) had previously shown that it minimises the build- up of polymeric material (I) and favours the production of the electrogenerated hydroquinones [27]. On the first scan, a single large oxidation peak is observed at $+0.50 \mathrm{~V}$ resulting in the generation of radical cations that undergo further reaction to form the various products highlighted in Scheme 2. Given the potential 
required to oxidise the salicylate, it can be anticipated that the resulting hydroquinones will be immediately oxidised and will be converted to the corresponding quinone forms (i.e. IV->V). Thus, on the reverse sweep, a series of reduction processes $(+0.16 \mathrm{~V}$ and $+0.25 \mathrm{~V})$ can be observed leading to the reduction of the electrogenerated quinones back to the hydroquinone (V $\rightarrow$ IV). The subsequent scans catch the hydroquinone-quinone redox transitions indicated within Scheme 3.

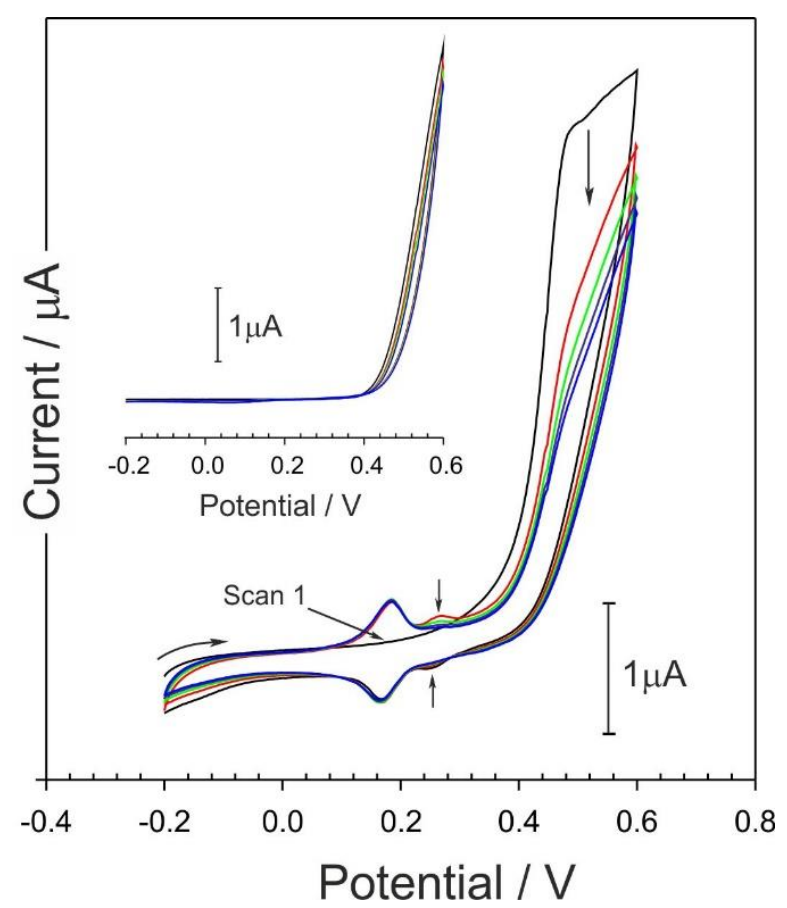

Figure 3. Cyclic voltammograms detailing the response of an anodised screen printed electrode towards the oxidation of salicylic acid ( $10 \mathrm{mM}, 0.1 \mathrm{M} \mathrm{NaOH}, 50 \mathrm{mV} / \mathrm{s})$. Inset: Response of an unanodised electrode in the same solution and scan rate. 


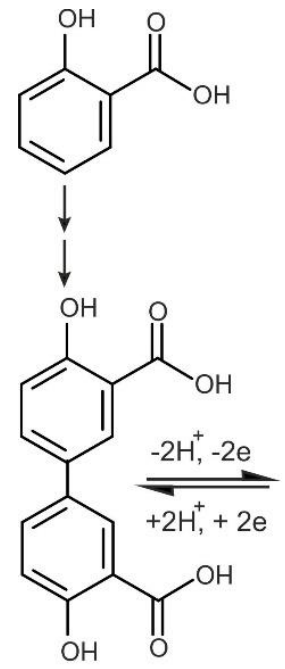

(IV)<smiles>O=C(O)C1=CC(=CC2=CC(C(=O)O)C=CC2=O)C=CC1=O</smiles>

(V)

Scheme 3. Hydroquinone-quinone redox transitions of the electrogenerated dimer resulting from the oxidation of salicylic acid.

The voltammograms highlight the fact that the peak magnitude relating to the dimer byproduct (IV) is relatively small in comparison to the direct oxidation of the salicylic acid and this can be attributed to the product spread indicated in Scheme 2.

\subsection{Development of a Detection Methodology}

It can be seen from Figure 3 that the dimer only appears after the initial electrochemical oxidation of the salicylate. The oxidation and hence quantification of the dimer could be achieved through performing two simultaneous scans - one to generate the dimer and the second to detect it - but such an approach would clearly be clumsy from a procedural perspective. Rather than employing a positive potential sweep, the scan direction was simply reversed - starting at a potential sufficiently positive to induce the immediate oxidation of the salicylate and facilitate the production of the dimer. As mentioned previously, at the initial potential through which the hydroquinone dimer is formed, it will be simultaneously oxidised to its corresponding quinone form. As the potential sweeps to less positive potentials, it was envisaged that the dimer would be reduced back to the hydroquinone form and thereby provide the analytical signal. Given the challenge of detecting low quantities of salicylate in urine, the 
higher sensitivity of square wave voltammetry was exploited as the principal instrumental technique.

Square wave voltammograms detailing the initial oxidation of salicylate and the subsequent reverse sweep are shown in Figure 4. The oxidation of the salicylate to the radical cation commences immediately and as the scan progresses towards less positive potentials the re-reduction of the former is captured as an easily identifiable peak process at $+0.57 \mathrm{~V}$. As the sweep continues, a second reduction peak emerges at $+0.19 \mathrm{~V}$ and this is attributed to the reduction of the electrochemically generated quinone dimer (IV). Increasing additions of salicylate to the test solution leads to the increase in the magnitude of both peak processes. The quinone dimer reduction was found to give a clear, well defined peak with a linear response over the range 16-300 $\mu \mathrm{M}$. It was envisaged that the low potential associated with the latter, rather than the direct reduction of the salicylate radical cation, would incur less interference from other matrix components. The sensitivity of the approach was found to be $0.0012 \mu \mathrm{A} / \mu \mathrm{M}$ with a detection limit of $5.6 \mu \mathrm{M}$ (based on $3 \mathrm{~s} / \mathrm{b}$ ). It should be noted that the range and detection limit are sufficient for detecting free salicylate within urine at supratherapeutic doses and those concentrations characteristic of poisoning $[14,15,30-32]$.

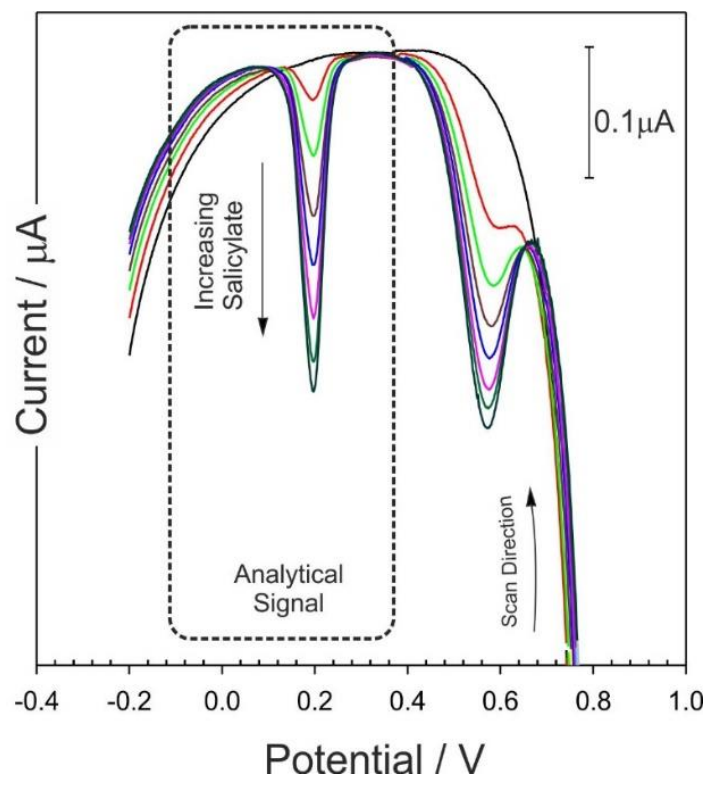

Figure 4. Square wave voltammograms detailing the response of the anodised screen printed electrode towards increasing concentrations of salicylate (16 $\mu \mathrm{M}$ increments) in $0.1 \mathrm{M} \mathrm{NaOH}$. 
Electrodes used to assess quantification of the dimer were found to retain a response to the dimer when placed in fresh electrolyte devoid of any added salicylate indicating that there is an absorptive component in the interaction of the dimer with the anodised carbon surface. The possibility of solution carry-over was excluded through rigorous rinsing of the electrode configuration prior to commencing what should have been a blank scan. Despite such precautions, the dimer reduction peak at $+0.19 \mathrm{~V}$ - exemplified in Figure 4 - was still observed albeit at a much lower intensity. The adsorptive interaction of the dimer at the carbon surface was further investigated using a higher concentration of the salicylate. An anodised screen printed electrode was scanned once in $10 \mathrm{mM}$ salicylate in $0.1 \mathrm{M} \mathrm{NaOH}$ as per the scan parameters detailed previously (Figure 4). The electrode was removed and rinsed to remove excess salicylate solution. The electrode was then placed in fresh $0.1 \mathrm{M} \mathrm{NaOH}$ and square wave voltammograms recorded at 2 minute intervals. The responses obtained are detailed in Figure $5 \mathrm{~A}$. On the first scan, it is notable that the peak associated with the reduction of the salicylate radical cation $(+0.57 \mathrm{~V})$ is greatly reduced and can be attributed to residual salicylate entrapped within the porous structure of the printed electrode (highlighted previously in Figure 1). As the potential is swept to less positive potentials, the reduction of the dimer is clearly observed. Again, it is worthwhile noting the relative magnitude of the peak in comparison to the residual salicylate. The magnitude of the dimer reduction process decreases with each consecutive scan and can be attributed to the gradual loss of the reduced form into the bulk of the solution.

The process was repeated but, rather than monitor the loss of the dimer in $\mathrm{NaOH}, \mathrm{pH} 7$ phosphate buffer was used. Similar peak processes were observed as those detailed in Figure 5A but the rate at which the peak decreased was markedly different and are compared in Figure 5B. The difference between the responses observed in $\mathrm{NaOH}$ and those in $\mathrm{pH} 7$ buffer could be attributed to the effect of the prevailing $\mathrm{pH}$ on the solubility of the dimer. It was envisaged that upon reduction of the dimer to the hydroquinone form, the strong alkaline conditions would induce deprotonation of both the phenolic and carboxylate group with the charged nature of the molecule increasing its hydrophilicity and assist its loss to the bulk of the solution. In contrast, only the carboxylate will be deprotonated in $\mathrm{pH} 7$ buffer (pKa of the phenol 10) and thus the loss to the solution bulk will be slower. 

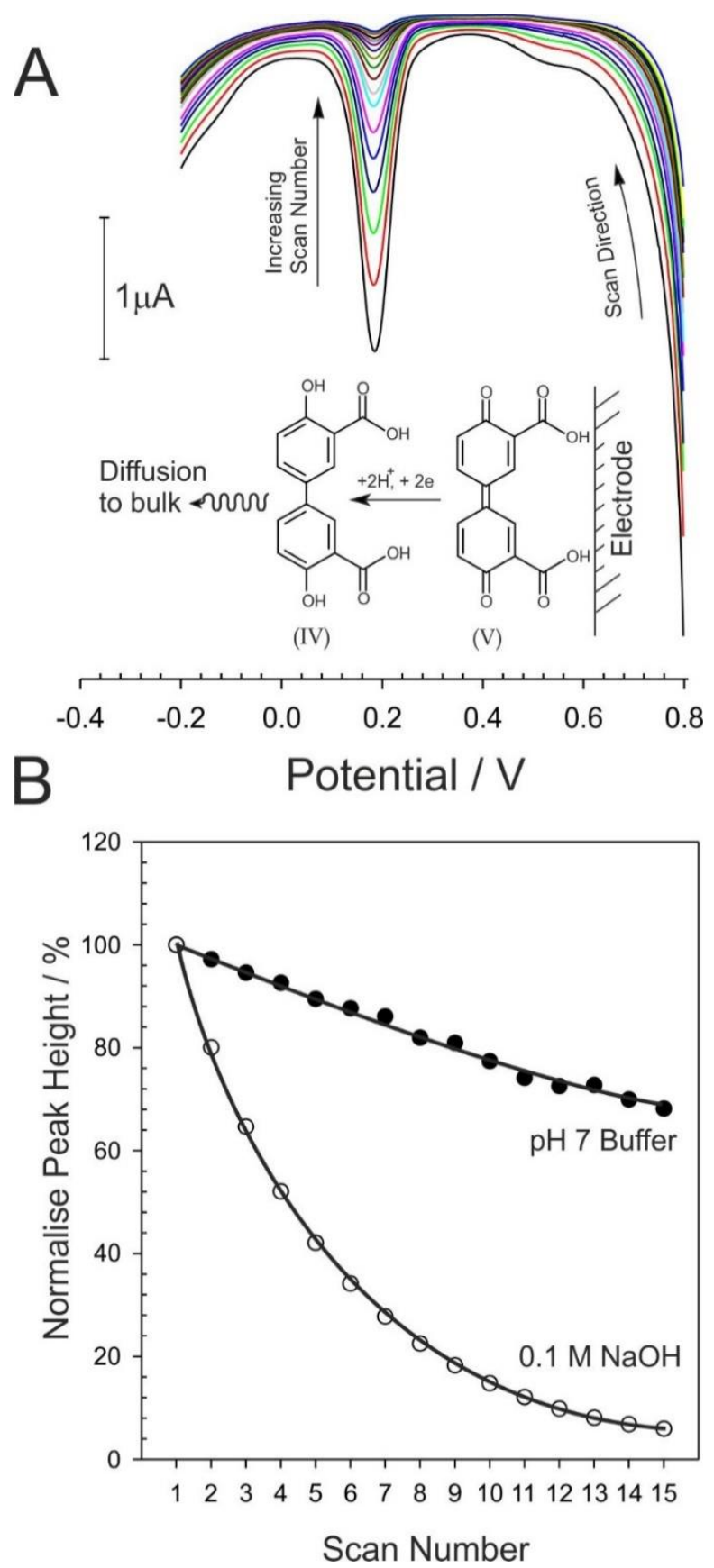

Figure 5. A) Consecutive square wave voltammograms detailing the response of an anodised SPE in $0.1 \mathrm{M}$ $\mathrm{NaOH}$ after an initial scan in a solution containing $10 \mathrm{mM}$ salicylic acid. B) Influence of $\mathrm{pH}$ on dimer peak height with consecutive scanning. 


\subsection{Recovery of Salicylate in Human Urine}

The electroanalytical capability of the anodised screen-printed sensors within urine was investigated through assessing the recovery of $100 \mu \mathrm{M}$ salicylate within human urine. Square wave voltammetry was again adopted as the principal technique with the reduction of the dimer used as the analytical target. Urine was spiked with $100 \mu \mathrm{M}$ salicylate as standard addition protocol involving sequential additions of $50 \mu \mathrm{M}$ salicylate. The initial spike was chosen to reflect previous studies by Morra and coworkers looking at the percutaneous absorption of a salicylate ointment where the excretion of free salicylate in urine was found to be in the range of $15 \mathrm{mg} / \mathrm{L}(109 \mu \mathrm{M})$ [30]. The test sample was $9 \mathrm{~mL}$ of $0.1 \mathrm{M} \mathrm{NaOH}$ followed by $1 \mathrm{~mL}$ of the urine / spike urine. It was necessary to retain the alkaline test medium to ensure the conversion of the dimer and to facilitate its desorption. A delay of 5 minutes was used between scans to ensure the latter did not influence subsequent scans. Representative voltammograms are detailed in Figure 6.

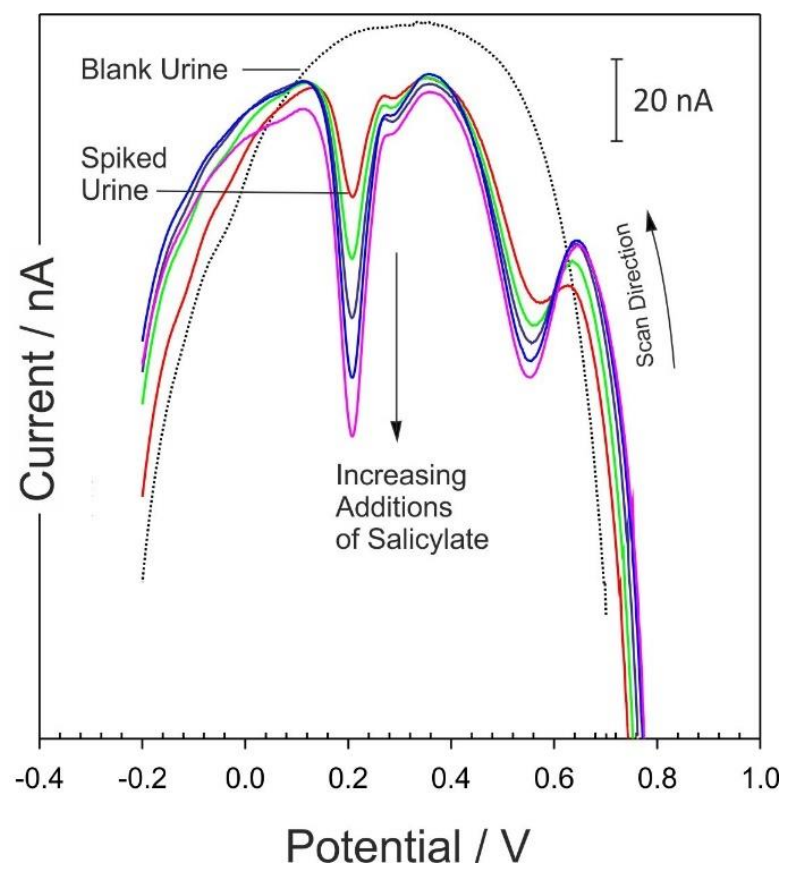

Figure 6. Square wave voltammograms detailing the recovery of $100 \mu \mathrm{M}$ salicylate from human urine through the consecutive additions of $50 \mu \mathrm{M}$ Standard salicylate. 
It is worthwhile noting that on the blank urine scan, there are no observable electrode processes within the potential window being examined. This is in marked contrast to the direct oxidation processes previously highlighted in Figure 2. The analysis of the spiked urine results in a well defined peak - similar to those observed Figure 4. The recovery experiments were conducted in triplicate and the results obtained are summarised in Table 1. It is clear from the responses observed in Figure 6 and the subsequent recovery experiments that the assay system proposed here can work within those limits with little interference from other endogenous components.

Table 1. Recovery of $100 \mu \mathrm{M}$ Salicylate from Human Urine

\begin{tabular}{ccccc} 
Sample & Gender & $\begin{array}{c}\text { Recovery } \\
\%\end{array}$ & N & \%RSD \\
\hline 1 & F & 99.98 & 3 & 0.61 \\
2 & F & 99.06 & 3 & 1.87 \\
3 & M & 99.81 & 3 & 3.22 \\
4 & M & 98.84 & 3 & 4.91 \\
\hline
\end{tabular}

An important observation from these investigations has been the relative lack of surface fouling - either as a consequence of the electrode processes or through non specific binding of other matrix components. The electrodes were left within the urine sample for upwards of 5 minutes during which time there was no noticeable deterioration in the response. In contrast, the standard addition procedure which required repetitive scanning of the same solution yielded excellent recovery of the spiked salicylate. Although the preliminary responses indicate no issues with surface fouling and that the electrodes could, in principle, be used for repeated measurements, it is envisaged that the final deployment would adopt a single use format similar to that used in portable glucose monitors.

\subsection{Discussion}

Patients attending Accident and Emergency services exhibiting a range of symptoms such as vomiting, abdominal pain, tinnitus, tachycardia and tachypnea could all too easily be suffering 
from salicylate poisoning[33-36]. The situation can be particularly complicated in paediatric cases where there can be a reluctance or inability of the subject to communicate. In many cases, the clinician will request a serum sample to determine the presence of salicylate as a matter of routine. This arises from the fact that, in many cases, the patient themselves may be unaware of the possibility of salicylate intoxication as the agent is commonplace in many OTC preparations[14,37] and there can be confusion over the correct application. The use of qualitative urine tests based on either Ferric ion complexation or Trinder's reagent has been advocated as a means of rapidly ascertaining whether salicylate poisoning is an underlying cause $[33,36]$. While the application of such tests could be beneficial it must be noted that their application can be contentious and procedurally problematic in a busy clinical emergency environment where there is often little opportunity to perform clinical chemistry. Moreover, the results can be subjective and subject to interference from other matric constituents giving rise to false positives[33]. Such issues can compromise clinician trust in such tests with a serum sample request being a default that effectively negates conducting the original spot test.

It is little surprise therefore that there has long been considerable interest in the development of simple sensing systems that could rapidly detect salicylate and provide some quantitative measure of the latter concentration. In addition to the direct electrochemical systems mentioned previously, a large number of spectroscopic methodologies have been applied and have included: molecularly imprinted polymers based on fluorescent terbium complexes[38], macromolecular Schiff bases [39], silica-titania xerogels[40] and thiourea optodes[41]. These systems exhibit detection limits in the range of $10^{-4}$ to $10^{-7} \mathrm{M}$ and hence are competitive with the printed electrode described here. It is the complexity of the competing systems and the lack of disposability however must be noted. Screen printed sensors are particularly amenable to mass manufacture and a large number of variants are commercially available (c.f. Dropsens.com). A critical advantage of the system advocated here is the fact that the sensor does not require extensive modification with nanoparticles [18,19], graphene $[23,24]$ or enzymes [25]. The reagentless nature provides a procedurally simple solution with a clear analytical signal arising from the dimer's reduction peak process. 


\section{Conclusions}

The foundations of a sensor capable of quantifying salicylate within urine using an indirect methodology has been demonstrated. The system is reagentless and possesses sufficient sensitivity to enable the rapid assessment of supratherapeutic doses. Although the outcomes are preliminary in nature, the sensor has been shown to be free of the interferences that can hamper direct methods. The foundations of a simple system that can be used for the point of care assessment of salicylate level have been laid and could be a more reliable method than those spot tests based on ferric ion or Trinder's reagent.

\section{Acknowledgements}

The authors thank the Department of Employment and Learning (DEL) Northern Ireland and ECLab Ltd for supporting this work.

\section{References}

1. Clarke TC, Nahin RL, Barnes PM, Stussman BJ, Use of Complementary Health Approaches for Musculoskeletal Pain Disorders Among Adults: United States, 2012, National Health Statistics Reports, 98,October 12, 2016.

2. Gittelman DK. Chronic salicylate intoxication. South Med J. 1993;86(6):683-685. National Center for Health Statistics New report finds pain affects millions of Americans. Press release issued by CDC; 2014. http://www.cdc.gov/nchs/pressroom/06facts/hus06.htm

3. Centers for Disease Control and Prevention. Disability and health: Musculoskeletal disorders. Available from: http://www.cdc.gov/ncbddd/disabilityandhealth/relatedconditions.html.

4. Smith T, Lynch ME, Johnson J, Kawa K, Bauman H, Blumenthal M. Herbal and dietary supplement sales in the US increase 6/8\% in 2014. HerbalGram 2015;107: 52-59.

5. National Institutes of Health. National pain strategy: A comprehensive population health-level strategy for pain. Available: from:

https://iprcc.nih.gov/docs/HHSNational Pain Strategy.pdf

6. University of Maryland Medical Center. Complications of spine surgery: A patient's guide to complications of spine surgery. Available from:

http://umm.edu/programs/spine/health/guides/complications-of-spine-surgery

7. Agency for Healthcare Research and Quality. Noninvasive treatments for low back pain. 2016. National Institutes of Health. The NIH guide: new directions in pain research 1. Washington, DC; 1996. Available from: http://grants.nih.gov/grants/guide/pa-files/PA-98-102.html.

8. Databridage Market Research Reports, Global Topical Drug Delivery Market is poised to grow at 9.2\% till 2024 . Available from: http://databridgemarketresearch.com/reports/global-topical-drug-deliverymarket-trendsforecast-2024 
9. Terrie YC, Topical Analgesics 2011, September 16, Available from: http://www.pharmacytimes.com/

10. Peppin JF, Albrecht PJ, Argoff C, Gustorff B, Pappagallo M, Rice FL, WallaceMS, Skin Matters: A Review of Topical Treatments for Chronic Pain. Part One: Skin Physiology and Delivery Systems, Pain Ther. 2015; 4:17-32

11. FDA Consumer Health Information, Use Caution with Over-the-Counter Creams, Ointments, April 2008. Available from: https://www.fda.gov/ForConsumers/ConsumerUpdates/ucm049367.htm

12. Mowry JB, Spyker DA, Brooks DE, McMillan N, Schauben JL (2015) 2014 Annual Report of the American Association of Poison Control Centers' National Poison Data System (NPDS): 33rd Annual Report, Clinical Toxicology, 2016; 54: 924-1109

13. Anderson A, McConville A, Fanthorpe L and Davis J, Salicylate Poisoning Potential of Topical Pain Relief Agents: From Age Old Remedies to Engineered Smart Patches, Medicines, 2017; 4: 48; doi:10.3390/medicines4030048

14. Chyka PA, Erdman AR, Christianson G, Wax PM, Booze LL, Manoguerra AS, Caravati EM, Nelson LS, Olson KR, Cobaugh DJ, Troutman WG, Salicylate poisoning: An evidence based consensus guideline for out of hospital management. Clin. Toxicol. 2007; 45: 95-131.

15. Vree TB, Van Ewijk-Beneken Kolmer, EWJ, Verwey-Van Wissen CPW, Hekster YA, Effect of urinary pH on the pharmacokinetics of salicylic acid, with its glycine and glucuronide conjugates in human. Int. J. Clin. Pharmacol. Ther. 1994; 32: 550-558.

16. Flomenbaum NE, Goldfrank LP, Hoffman RS, Howland MA, Lewlin NA, Nelson LS, Salicylates. In Goldfrank's Toxicologic Emergencies, 8th ed.; McGraw-Hill: New York, NY, USA, 2006.

17. Supalkova V, Petrek J, Havel L, Krizkova S, Petrlova J, Adam V, Potesil D, Babula P, Beklova M, Horna A, Kizek R, Electrochemical sensors for detection of acetylsalicylic acid, Sensors, 2006; 6: 1483-1497.

18. Sun LJ, Pan ZQ, Xie J, Liu XJ, Sun FT, Song FM, Bao N, Gu HY, Electrocatalytic activity of salicylic acid on Au@Fe304 nanocomposites modified electrode and its detection in tomato leaves infected with Botrytis cinerea, J. Electroanal. Chem. 2013; 706: 127-132.

19. Wang Z, Wei F, Liu SY, Xu Q, Huang JY, Dong XY, Yu JH, Yang Q, Zhao YD, Chen H, Electrocatalytic oxidation of phytohormone salicylic acid at copper nanoparticles-modified gold electrode and its detection in oilseed rape infected with fungal pathogen Sclerotinia sclerotiorum, Talanta 2010; 80: 1277-1281.

20. Wang Z, Ai F, Xu Q, Yang Q, Yu JH, Huang WH, Zhao YD, Electrocatalytic activity of salicylic acid on the platinum nanoparticles modified electrode by electrochemical deposition, Colloid. Surface B 2010; 76: 370-374.

21. Chrzescijanska E, Wudarska E, Kusmierek E, Rynkowski J, Study of acetylsalicylic acid electroreduction behaviour at platinum electrode, J. Electroanal. Chem. 2014; 713: 17-21.

22. Gonzalez-Sanchez MI, Lee PT, Guy RH, Compton RG, In situ detection of salicylate in Ocimum basilicum plant leaves via reverse iontophoresis, Chemistry Communications, 2015; 51: 16534-16536

23. Patil SM, Sataraddi SR, Bagoji AM, Pathan RM, Nandibewoor ST, Electrochemical Behaviour of Graphene-Based Sensors on the Redox Mechanism of Aspirin, Electroanal. 2014; 26: 831-839.

24. Kruanetr S, Pollard P, Fernandez C, Prabhu R, Electrochemical Oxidation of Acetyl Salicylic Acid and its voltammetric sensing in real samples at a sensitive edge plane Pyrolytic Graphite Electrode modified with Graphene, Int. J. Electrochem. Sc. 2014; 9: 5699-5711.

25. Campanella L, Gregori E, Tomassetti M, Salicylic acid determination in cow urine and drugs using a bienzymatic sensor, Journal of Pharmaceutical and Biomedical Analysis, 2006; 42: 94-99

26. Fang $Y$, Bullock H, Lee SA, Sekar N, Eiteman MA, Whitman WB, Ramasamy RP, Detection of methyl salicylate using bi-enzyme electrochemical sensor consisting salicylate hydroxylase and tyrosinase, Biosensors and Bioelectronics, 2016; 85: 603-610

27. Park J, Eun C, Electrochemical Behavior and Determination of Salicylic Acid at Carbon-fiber Electrodes, Electrochimica Acta, 2016; 194: 346-356

28. Phair J, Newton L, McCormac C, Cardosi MF, Leslie R, Davis J, A disposable sensor for point of care wound pH monitoring, Analyst 2011; 136: 4692-4695

29. Anderson A, McHugh J, Benson J, Davis J, Investigating the use of endogenous quinoid moieties on carbon fibre as means of developing micro pH sensors, Materials Science and Engineering C, 2014; 43: 533-537

30. Morra P, Bartle WR, Walker SE, Serum concentrations of salicylic acid following topically applied salicylate derivatives. Ann. Pharmacother. 1996; 30: 935-940. 
31. Gilman AG, Rall TW, Nies AS, Taylor P (eds.) Goodman and Gilman's The Pharmacological Basis of Therapeutics. 8th ed. New York, NY. Pergamon Press, 1990 pps 649, 653.

32. Ellenhorn MJ and Barceloux DG (1988): Medical Toxicology - Diagnosis and Treatment of Human Poisoning, Elsevier 1988.

33. Weiner Al, Ko C, McKay CA, A Comparison of Two Bedside Tests for the Detection of Salicylates in Urine, Academic Emergency Medicine, 2000; 7: 834-836

34. Hoffman RJ, Nelson LS, Hoffman RS, Use of ferric chloride to identify salicylate-containing poisons, Journal of Toxicology- Clinical Toxicology, 2002; 40: 547-549

35. Berkovitch M, Uziel Y, Greenberg R, Chen-Levy Z, Arcusin M, Marcus O, Pinto O, Evans S, Matias A, Lahat E, False-high blood salicylate levels in neonates with hyperbilirubinemia, Therapeutic Drug Monitoring, 2000; 22: 757-761

36. Dasgupta A, Zaidi S, Johnson M, Chow L, Wells A, Use of fluorescence polarization immunoassay for salicylate to avoid positive/negative interference by bilirubin in the Trinder salicylate assay, Annals of Clinical Biochemistry, 2003; 40: 684-688

37. Yin HS, Parker RM, Wolf MS, Mendelsohn AL, Sanders LM, Vivar KL, Carney K, Cerra ME, Dreyer BP, Health Literacy Assessment of Labeling of Pediatric Nonprescription Medications: Examination of Characteristics that May Impair Parent Understanding, Academic Pediatrics, 2012; 12: 288-296

38. Huang JX, Hu YF, Hu YL, Li GK, Disposable terbium (III) salicylate complex imprinted membrane using solid phase surface fluorescence method for fast separation and detection of salicylic acid in pharmaceuticals and human urine, Talanta, 2013; 107: 49-54

39. Luo EP, Chai YQ, Yuan R, Dai JY, XU L, Highly salicylate-selective membrane electrode based on a new thiomacrocyclic Schiff base complex of binuclear copper(II) as neutral carrier, Desalination, 2009; 249: 615-620

40. Morosanova MA, Morosanova El, Silica-titania xerogel for solid phase spectrophotometric determination of salicylate and its derivatives in biological liquids and pharmaceuticals, Chemistry Central Journal, 2015; 9: Article Number: 64. DOI: 10.1186/s13065-015-0142-z

41. Abdel-Haleem FM, Highly selective thiourea-based bulk optode for determination of salicylate in spiked urine samples, Aspirin (R) and Aspocid (R), Sensors and Actuators B, 2016; 233: 257-262 